\title{
Sustentabilidade em meios de hospedagem no Brasil
}

Antônio Pedro Tessaro - Mestre em Engenharia. Faculdade de Tecnologia Senac Caçador - Brasil. tessaro@gegnet.com.br Elis Regina Mazzurana - Mestra em Produção Vegetal. Faculdade de Tecnologia Senac Caçador - Brasil. elismazzurana@gmail.com

\section{RESUMO}

O turismo é uma atividade realizada em todo o mundo e que pode gerar grandes impactos ao meio ambiente, nesse sentido, muitas ações de sustentabilidade vêm sendo desenvolvidas pelos órgãos responsáveis e pelos meios de hospedagem para que os efeitos dessa atividade sejam minimizados no meio ambiente. Neste trabalho foi realizado um estudo bibliográfico sobre as principais ações possíveis de implementação pelos meios de hospedagem no Brasil, visando atingir os critérios de sustentabilidade. Os principais pontos abordados foram o consumo de água e de energia nos meios de hospedagem, além de algumas medidas para sensibilização dos hóspedes em relação à sustentabilidade.

Palavras-chave: Turismo. Sustentabilidade. Meios de hospedagem. Hóspedes.

\section{Sustainability in accommodation facilities in Brazil}

\begin{abstract}
Tourism is an activity performed throughout the world and it can have large impacts on the environment. Thus, organizations related to environmental matters and the hospitality sector have developed many sustainability initiatives in order to minimize the effects of this activity on the environment. This research is a bibliographic study on the main actions that can be implemented by means of accommodation in Brazil to meet the sustainability criteria. The main issues addressed were water and electricity consumption in accommodation facilities, as well as some measures to raise guests` awareness in relation to sustainability.
\end{abstract}

Keywords: Tourism. Sustainability. Accommodation facilities. Guests. 


\section{INTRODUÇÃO}

O turismo é uma atividade de grande impacto social e econômico gerando muitos empregos em várias áreas, sendo um setor em expansão na busca de atrair cada vez mais clientes.

Nas últimas décadas, devido aos grandes impactos ambientais causados pelo homem, a questão ambiental virou o centro de atenção sendo considerada aspecto fundamental para aliar desenvolvimento econômico e sustentabilidade em todos os empreendimentos, inclusive nos meios de hospedagem. De acordo com a ABNT NBR 15401 (ABNT, 2006) entende-se por meio de hospedagem, um empreendimento, público ou privado, que forneça, dentre as suas atividades, serviços de acomodação.

Por meio de ações relacionadas à sustentabilidade, os meios de hospedagem podem alcançar vantagens competitivas, uma vez que, segundo Almeida (2016) para atingir a competitividade na área da sustentabilidade, além de melhorias básicas e isoladas, é necessário um trabalho de posicionamento estratégico constante, com adoção de medidas inovadoras que se diferenciem da concorrência.

Apesar de muitos administradores/empresários dos ramos de hotelaria e hospedagem apresentarem interesse pela questão ambiental e praticarem ações em prol do meio ambiente em seus estabelecimentos, ainda existe uma carência significativa em termos de conhecimento sobre o assunto e das práticas ambientais em seu setor (ALMEIDA; FREITAS, 2009). Desta forma, torna-se necessário conhecer as principais ações que podem ser implementadas pelos meios de hospedagem no Brasil, visando atingir os critérios de sustentabilidade, contribuindo com a melhoria da qualidade nos meios de hospedagem e com o desenvolvimento sustentável.

O objetivo geral é realizar um estudo bibliográfico sobre as principais ações que podem ser implementadas pelos meios de hospedagem no Brasil, visando atingir os critérios de sustentabilidade.

Os objetivos específicos são:

- Descrever brevemente sobre o avanço da sustentabilidade em meios de hospedagem no Brasil;

- Pontuar os principais requisitos de sustentabilidade aplicados nos meios de hospedagem no Brasil em relação ao consumo de água e energia;

- Apresentar as principais medidas tomadas pelos meios de hospedagem para sensibilização dos turistas quanto à sustentabilidade.

\section{SUSTENTABILIDADE EM MEIOS DE HOSPEDAGEM NO BRASIL}

De acordo com o Ministério do Turismo (2016) o turismo no Brasil vem crescendo nos últimos anos, onde o mercado formal de trabalho nas Atividades Características do Turismo - ACTs, passou de 1,71 milhões de pessoas empregadas, em 2002, para 2,27 milhões de pessoas empregadas em 2008, o que representa um crescimento da ordem de $32,70 \%$ em seis anos. No ano de 2008, este número correspondeu a 5,76 \% do total de empregos formais acumulados no País.

O crescimento no turismo vem acompanhado de um crescimento no ramo dos meios de hospedagem, gerando grande impacto aos recursos naturais, principalmente no uso da água, energia elétrica, uso da terra, flora e fauna nativas (especialmente na construção de novos empreendimentos de hospedagem), ocasionando, além disso, a geração de resíduos sólidos e efluentes líquidos, emissão de gases e ruídos e poluição visual (CENTENO, 2004). 
Nos últimos anos, vários trabalhos acadêmicos vêm focando no turismo e no seu desenvolvimento sustentável, Entretanto, deve-se lembrar que tornar o turismo mais sustentável significa ir além de gerir os seus efeitos negativos/positivos no ambiente, trata-se de beneficiar as comunidades locais, do ponto de vista econômico e social, aumentando a consciência e suporte à conservação do meio ambiente, baseando-se nos três pilares do desenvolvimento sustentável: crescimento econômico, proteção ambiental e progresso social (ALMEIDA, 2016).

A ideia de sustentabilidade no turismo no Brasil surgiu em 2001, com o objetivo de aumentar a competitividade de pequenos e médios meios de hospedagem por meio da implementação de boas práticas sustentáveis, através da normalização e certificação (MATOS; COSTA, 2012). Mas para que o turismo ecologicamente sustentável se torne uma realidade, são necessárias iniciativas por parte de todos os envolvidos no cenário turístico, começando com os próprios turistas (ALVES; CONTO, 2008).

Os meios de hospedagem podem funcionar como agentes multiplicadores das questões ambientais no processo do turismo, representando papel fundamental na responsabilidade ambiental, conscientizando seus hóspedes. Ao gerar um senso de responsabilidade pelos danos ao meio ambiente, entende-se que esses hóspedes tomarão uma posição ética e responsável em relação às questões ambientais (ALVES; CONTO, 2008).

Em 2006, com o objetivo de melhorar a qualidade e a competitividade no setor turístico, foi criada a norma ABNT NBR 15401 (ABNT, 2006), constituindo-se em uma referência para os empreendimentos turísticos implementarem e manterem consistentemente práticas que contribuam para o objetivo maior do turismo sustentável.

De acordo com essa norma, a sustentabilidade do turismo é fundamentada por um conjunto mínimo de princípios que, no Brasil, fundamentam-se em alguns princípios estabelecidos pelo Conselho Brasileiro para o Turismo Sustentável (CBTS), constituindo-se como referência nacional para o Turismo Sustentável. São eles:

1. Respeitar a legislação vigente;

2. Garantir os direitos das populações locais;

3. Conservar o ambiente natural e sua biodiversidade;

4. Considerar o patrimônio cultural e valores locais;

5. Estimular o desenvolvimento social e econômico dos destinos turísticos;

6. Garantir a qualidade dos produtos, processos e atitudes;

7. Estabelecer o planejamento e a gestão responsáveis.

Visando garantir esses princípios estabelecidos, os meios de hospedagem apresentam rotinas bem definidas de operação, como o consumo de água, consumo de energia elétrica, geração de resíduos sólidos, emissões de efluentes líquidos, entre outros (ALVES; CONTO, 2008).

\subsection{Consumo de água nos meios de hospedagem}

Conforme a NBR 15401, sobre conservação e gestão do uso de água:

O empreendimento deve planejar e implementar medidas que asseguram que a captação e o consumo de água não comprometam a sua disponibilidade para as comunidades locais, flora e fauna, a vazão dos corpos d'água e o nível e proteção dos mananciais, preservando o equilíbrio dos ecossistemas. As medidas devem incluir ações tais como: utilização de dispositivos para economia de água (como, por exemplo, torneiras e válvulas redutoras de consumo em banheiros, lavabos, chuveiros e descargas); programa específico como troca não diária de roupa de cama e toalhas; programas de inspeção periódica nas canalizações e sua manutenção, com vistas à minimização das fugas de água. Devem ser mantidos 
registros dessas inspeções e reparos; captação e armazenamento de águas pluviais; preservação e revitalização dos mananciais de água (ABNT, 2006, p. 12).

Algumas medidas importantes para redução do consumo de água em unidades habitacionais (UH's) são citadas por ABNT/SEBRAE (2012, p. 59):

- Realizar a captação de águas das chuvas para utilizações menos nobres como, por exemplo, descargas, limpeza de pisos e jardins, entre outros;

- Utilizar chuveiros econômicos' nas UH's;

- Utilizar arejadores², válvulas redutoras e/ou controladores do fluxo de água nas torneiras, quer nas automatizadas, quer nas torneiras controladas por sensores;

- Utilizar descarga econômica

- Estabelecer procedimentos de economia e informação para a troca de roupa de cama, banho, toalhas de mesa, entre outros;

- Adotar um sistema rápido e eficaz de detecção de fendas e vazamentos nas torneiras e sanitários;

- Adotar um programa de manutenção e prevenção para sistemas de ar condicionado, canalização e acessórios derivados, equipamentos de cozinha e equipamentos de lavanderia;

- Realizar o monitoramento, registro e análise do consumo de água regularmente; - Realizar, para a gestão, relatórios periódicos sobre a utilização de água e procedimentos referentes a consertos e manutenção;

- Instalar dispositivos para a recuperação do vapor condensado nas caldeiras;

- Modificar o sistema de canalização de forma a recuperar, tratar e armazenar a água não muito poluída, utilizada em determinadas operações (ex. na lavagem dos vegetais). Esta pode ser utilizada nas descargas por exemplo;

- Disponibilizar a opção de substituição das toalhas e lençóis, somente quando pretendida pelos hospedes;

- Aos meios de hospedagem que possuem piscina é essencial o monitoramento da qualidade de água, além de procedimentos que minimizem o consumo. Como por exemplo, utilizar produtos alternativos ao cloro para a sanitização das piscinas (ex. sistema de ozono).

Conforme observa-se acima, algumas medidas apresentadas são de fácil implementação e aquelas que demandam investimentos, não oneram de sobremaneira o empreendimento, pois comercialmente são de uso corrente, e disponíveis em seus produtos de linha, encontrados em lojas de materiais de construção. Outras medidas, porém, são de caráter administrativo, o qual devem passar pelo crivo da direção da empresa, e que podem passar por um cronograma de investimentos, para não sobrecarregar o desempenho financeiro da mesma.

\subsection{Consumo de energia elétrica nos meios de hospedagem}

Dentro de um meio de hospedagem, visando dar conforto aos hóspedes, existem várias funcionalidades que dependem do uso de energia elétrica. Desde um chuveiro, tomadas disponíveis para uso de notebooks, entre outros. Assim, o consumo de energia elétrica pode ficar representativo dentro da estrutura, colaborando por exemplo, no aumento de custos repassados para os clientes.

\footnotetext{
${ }^{1}$ Cinco minutos. É o tempo recomendado pela empresa de abastecimento de água de São Paulo para evitar desperdício. Um banho de ducha de 15 minutos consome 243 litros de água. Essa quantidade é mais que o dobro do que a pessoa deveria consumir para todas as atividades do dia, segundo a Organização Mundial da Saúde.

${ }^{2}$ Uma torneira convencional dispensa de 5 a 20 litros/minuto. Passando para 1.8 litros/minuto, sem perda de conforto, há uma economia entre $64 \%$ a $91 \%$.

${ }^{3} \mathrm{O}$ produto proporciona, de forma segura, uma economia de até $33 \%$ no consumo de água.
} 
O aumento de tarifa com as mudanças estruturais do setor elétrico, a preocupação em reduzir os impactos ambientais e incentivar energias alternativas, tem aumentado a preocupação com a redução do consumo e uso racional de energia elétrica no Brasil (ASSIS; CONTO, 2012). Em uma perspectiva econômica no que se refere ao conforto, deve-se ter em mente que o consumo de energia elétrica deverá ser racionalizado.

Conforme ABNT (2006, p. 13) que trata sobre a eficiência energética em suas diversas linhas de ação,

O empreendimento deve planejar e implementar medidas para minimizar o consumo de energia, em particular de fontes não renováveis.

5.6.1 O empreendimento deve controlar e registrar o consumo de energia (em quilowatts por hóspede/noite) de fontes externas e de fontes próprias renováveis e não renováveis.

5.6.2 O empreendimento deve estabelecer metas de consumo, considerando a demanda, o seu desempenho histórico e o levantamento de referências regionais de consumo em estabelecimentos de mesmo padrão.

As metas de consumo devem considerar o "consumo fixo" e o "consumo variável". 5.6.3 É recomendável que o empreendimento faça uso de fontes de energia renováveis, na extensão e de acordo com as suas especificidades e tecnologias disponíveis, levando em conta os aspectos de viabilidade econômica e ambiental. Dentre estas convém considerar o uso de tecnologia solar ou outras de menor impacto ambiental.

5.6.4 O empreendimento deve ter implementado um procedimento para assegurar que as luzes e equipamentos elétricos permaneçam ligados apenas quando necessário.

5.6.5 Os procedimentos de aquisição de equipamentos e insumos que consomem energia (como lâmpadas, equipamentos de refrigeração, geladeiras e frigoríficos, fogões, aquecedores, lavadoras de roupa, etc.) devem incluir como critério sua eficiência energética e a possibilidade do uso de fontes de energia alternativas.

5.6.6 A arquitetura das construções deve utilizar as técnicas para maximizar a eficiência energética, tais como, por exemplo:

- Isolamento térmico de paredes e forros;

- Ventilação natural;

- Otimização do uso da sombra e insolejamento;

- Otimização do uso da iluminação natural;

- Minimização das fugas e perdas de calor nas instalações hidráulicas, de aquecimento e de refrigeração;

- Utilização de equipamentos e dispositivos de aquecimento ou refrigeração com eficiência energética maximizada.

5.6.7 O empreendimento deve planejar e implementar medidas para reduzir o consumo de energia dos meios de transporte próprios e utilizados nas suas atividades.

NOTA Tais medidas podem incluir o uso de veículos eficientes do ponto de vista energético, efetuar as manutenções regulares, planejar o uso da frota otimizando a sua eficiência, escolhendo trajetos e horários mais eficientes, treinamento dos motoristas em condução econômica e outras medidas equivalentes.

De acordo com Melo (2005) para uma análise apurada do histórico de consumo e demanda de um edifício deve-se utilizar dados completos de um ciclo anual de medições, e quando possível utilizar os registros de vários anos. A comparação de alguns dados anuais, indicam mudanças em padrões de consumo de energia do prédio, como instalação de centrais de processamento de dados, ou de novos aparelhos de climatização ou até mesmo, a introdução de inovações tecnológicas, como microcomputadores e equipamentos elétricos. Portanto, um bom controle no consumo energético, evidenciará como está o comportamento do cliente, considerando assim as suas sazonalidades. 
Sobre o item 5.6.3 da norma acima referenciada, que trata da energia solar, tem-se que:

A radiação solar pode se transformar em energia elétrica por meio de placas de células fotovoltaicas, que a armazenam em baterias. Essa energia pode ser utilizada em aparelhos elétricos e eletrônicos (de baixa voltagem, preferencialmente, para evitar o uso de transformadores). Como a tecnologia é relativamente nova, seu custo ainda é alto, o que pode inviabilizar o atendimento total da demanda energética de um meio de hospedagem (SANTANDER, 2010, p. 24).

Em relação as lâmpadas ligadas desnecessariamente, é possível instalar sensores de presença, que podem substituir os interruptores ou colocados no teto próximos às luminárias, sendo que os equipamentos disponíveis no hotel devem ser enquadrados no Selo Procel (Figura 1), cuja finalidade se constitui como uma ferramenta simples, mas eficaz, permitindo ao consumidor conhecer, entre os equipamentos e eletrodomésticos à disposição no mercado, os mais eficientes no consumo de energia (PROCEL INFO, 2016).

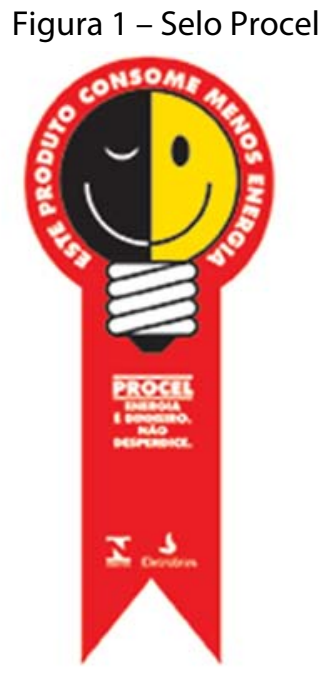

Fonte: Procel Info (2016)

De acordo com Almeida (2016) a iluminação representa cerca de $15-25 \%$ do consumo elétrico do hotel, então, esta realmente se efetiva em uma preocupação quando se considera o uso de lâmpadas mais eficientes, ou seja, que demandam menos trocas em função de desgastes, sendo mais econômicas. Uma boa opção, no contexto das novas tecnologias, é a lâmpada LED (Light Emitter Diode), que pode ser integrada aos mais diferentes ambientes, como corredores, quartos e outros.

Um ponto importante a ser pensado pelos meios de hospedagem é a questão de rouparia. Medidas que incentivem o hóspede a evitar trocas desnecessárias de roupas de cama ou banho são muito eficientes.

De acordo com Santander (2010, p. 26):

A rouparia é um dos itens mais importantes para o bom funcionamento de um meio de hospedagem. Secadoras elétricas consomem muita energia e nem sempre é possível contar apenas com o varal externo. Ao lado da lavanderia, reserve espaço para construir uma "estufa natural", coberta com telhas transparentes ou vidro, para instalar varais - e economizar muita energia elétrica. 
Nesse sentido, vale salientar que as medidas de redução de consumo de energia elétrica por si só, não geram efeitos, pois dependem da ação intensiva dos funcionários e da diretoria dos meios de hospedagem, norteando para que ações dessa natureza tenham continuidade, mas antes disso, se tornem prática dos estabelecimentos.

\subsection{Sensibilização para os hóspedes em relação à sustentabilidade}

A questão da sustentabilidade e da responsabilidade ambiental deve ser uma preocupação coletiva, indo além dos estabelecimentos de hospedagem. É importante que o turista também se preocupe com as questões ambientais e procure por meios de hospedagem que ofereçam ações que melhor se adequem à sustentabilidade. Entretanto, de acordo com a Associação Nacional de Pesquisa e Pós-Graduação em Turismo (ANPTUR, 2009) relativamente poucos turistas parecem tomar decisões movidos por preocupações ambientais.

Na contramão desse comportamento, nos últimos anos vêm surgindo uma nova categoria de turista, chamado "turista verde", esse termo está diretamente ligado ao meio ambiente e a forma de consumir os produtos turísticos (MARINHO; MARTINS, 2010). Desta maneira, os empreendedores turísticos têm se preocupado em aderir às medidas sustentáveis visando atrair esse público.

O Ministério do Turismo, em parceria com o Programa das Nações Unidas para o Meio Ambiente (PNUMA), além dos Ministérios do Meio Ambiente e do Esporte, promovem a campanha "Passaporte Verde", estimulando viajantes e empresários a fazerem escolhas sustentáveis. A campanha apresenta 10 dicas que podem ser utilizadas pelos turistas durante suas viagens, visando a consciência ambiental. Estas dicas assim orientam:

1. Escolher voo direto, o turista economiza tempo ao mesmo que reduz as emissões de carbono;

2. Procurar não se hospedar em estabelecimentos construídos em Áreas de Preservação Permanente, como beiras de rios, lagos e praias, topos de morros ou encostas muito inclinadas, restingas e manguezais e outros ecossistemas frágeis. Outra dica é ficar em hotéis próximos aos atrativos que deseja conhecer para economizar em transporte e reduzir a emissão de poluentes;

3. Buscar roteiros que permitam conhecer a cultura e as belezas naturais e vivenciar o ritmo local;

4. Levar uma garrafa de água reutilizável, em vez de comprar garrafinhas descartáveis e aumentar a geração de resíduos;

5. Em ambientes naturais, recolher o lixo que produzir;

6. Tomar cuidado especial com sacolas plásticas na praia, elas podem voar e ser ingeridas pela fauna marinha;

7. Dar preferência ao transporte público e, se alugar um carro, escolher o modelo mais econômico possível para reduzir o consumo de combustível. Nos carros flex, optar pelo etanol que é uma fonte renovável;

8. Ao fazer as malas, escolher roupas que não precisam ser passadas, assim é possível reduzir o consumo de energia;

9. Ao ir às compras durante a viagem, dar preferência aos produtos locais, essa é uma forma de contribuir com a geração de empregos e aumentar a renda dos moradores;

10. Para economizar água é só pedir para trocar toalhas e enxoval no hotel se for realmente necessário. Isso ajuda a minimizar a estatística de que cada turista consome quase três vezes mais água do que os residentes (MINISTÉRIO DO TURISMO, 2016). 


\section{CONCLUSÃO}

Este artigo apresentou várias descrições associadas às ações de sustentabilidade para o consumo de água, energia elétrica, bem como a sensibilização dos hóspedes para que isso possa ocorrer de forma natural.

As ações de um modo geral são simples de serem implementadas, sendo parcela delas, de responsabilidade dos meios de hospedagem, quando se trata de infraestrutura com equipamentos e dispositivos mais modernos e eficientes; e parcela de responsabilidade das pessoas que escolhem os locais pelos mais diferentes motivos e/ou situações.

Exemplos como diminuição do consumo de energia elétrica em um banho, obrigatoriamente incide na redução do tempo de uso do chuveiro elétrico, quando for o caso. Assim, como um simples ato de tomar água em um bebedouro com copos descartáveis é uma questão cultural que pode ser mudada quando o cliente utiliza uma garrafa de água podendo reutilizá-la.

Por fim, ações como as apresentadas são importantes e necessárias para que se mude o conceito a respeito da sustentabilidade, especialmente quando se trata de classificação de meios de hospedagem.

\section{REFERÊNCIAS}

ASSOCIAÇÃO BRASILEIRA DE NORMAS TÉCNICAS (ABNT). NBR 15401 - Meios de hospedagem: Sistema de gestão da sustentabilidade - Requisitos. ABNT - Associação Brasileira de Normas Técnicas, 2006.

ASSOCIAÇÃO BRASILEIRA DE NORMAS TÉCNICAS (ABNT)/SEBRAE. Meios de Hospedagem: Sistema de gestão da sustentabilidade / Associação Brasileira de Normas Técnicas, Serviço Brasileiro de Apoio às Micro e Pequenas Empresas. Rio de Janeiro: ABNT; SEBRAE, 2012.

ALMEIDA, Joana Branquinho Ramos de. Sustentabilidade em hotelaria: uma análise da infusão/difusão em hotéis de Lisboa. 2016. Dissertação (Mestrado) - Universidade Europeia, Lisboa.

ALMEIDA, Georgia Maria Mangueira de; FREITAS, André Luís Policani. Avaliação da consciência ambiental em meios de hospedagem. In: Encontro Nacional de Engenharia de Produção, 29., 2009, Salvador. Anais... Salvador: ABEPRO, 2009. p. 01-14.

ALVES, Thiago José Costa; CONTO, Suzana Maria de. Informações de hóspedes sobre compromisso com o meio ambiente. In: Seminário de Pesquisa em Turismo do MERCOSUL (SeminTUR), 5., 2008, Caxias do Sul. Anais... Caxias do Sul: Universidade de Caxias do Sul, 2008. p. 01-14.

ANPTUR - Associação Nacional de Pesquisa e Pós-Graduação em Turismo. Informações de hóspedes sobre gerenciamento de resíduos sólidos como fator

decisivo na escolha do destino turístico. In: Seminário da Associação Brasileira de Pesquisa e PósGraduação em Turismo, 6., 2009, São Paulo. Anais... São Paulo: Universidade Anhembi Morumbi, 2009. p. 01-11.

ASSIS, Regina Cardona de; CONTO, Suzana Maria de. Eficiência energética em meios de hospedagem. In: Seminário de Pesquisa em Turismo do Mercosul, 7., 2012, Caxias do Sul. Anais do VII Seminário de Pesquisa em Turismo do Mercosul. Caxias do Sul: Universidade de Caxias do Sul, 2012. p. 01-15. 
CENTENO, Cláudia Rodrigues. Gestão ambiental em meios de hospedagem. 2004. TCC (Graduação) - Centro Universitário Metodista IPA, Porto Alegre.

MARINHO, Ana Carolina Pará; MARTINS, Cláudia Araújo de Menezes Gonçalves. Turista verde: uma análise do perfil e da escolha do seu destino turístico. Revista Eletrônica Aboré - Publicação da Escola Superior de Artes e Turismo, Manaus, n. 4, p. 121-132, dez. 2010

MATOS, Jaqueline Kropf Esteves de; COSTA, Maria Alice Nunes. Sustentabilidade nos meios de hospedagem no Brasil: a norma NBR 15401:2006. In: Congresso de Arquitetura, Turismo e Sustentabilidade, 1., 2012, Cataguases. Anais... Cataguases: CATS, 2012. p. 206-223.

MELO, Ana Paula. Avaliação computacional de estratégia para a redução do consumo de energia elétrica em um hotel de Florianópolis. 2005. TCC (Graduação) - Universidade Federal de Santa Catarina, Florianópolis.

MINISTÉRIO DO TURISMO. Dados e fatos: estudos, pesquisas e dados sobre o setor de turismo. [2016]. Disponível em: <http://www.turismo.gov.br/>. Acesso em: 06 jun. 2016.

PROCEL INFO. Centro Brasileiro de Informação de Eficiência Energética. Disponível em $<$ http://www.procelinfo.com.br>. Acesso em: 01 set. 2016.

SANTANDER. Guia de sustentabilidade: meios de hospedagem. [2010]. Disponível em <https://sustentabilidade.santander.com.br>. Acesso em: 06 jun. 2016. 